\title{
Review on Essential Oils and Their Corrosion-inhibiting Properties
}

\author{
Malick Bathily ${ }^{1,2}$, Baba Ngom ${ }^{1,}$, , Diadioly Gassama ${ }^{2}$, Seni Tamba ${ }^{1}$ \\ ${ }^{1}$ Laboratory of Sciences and Technologies of Water and Environment (LaSTEE), Polytechnic School of Thies (EPT), Thies, Senegal \\ ${ }^{2}$ UFR Sciences \& Technologies, University Iba Der Thiam of Thies, Thies, Senegal
}

Email address:

bngom@ept.sn (B. Ngom)

${ }^{*}$ Corresponding author

To cite this article:

Malick Bathily, Baba Ngom, Diadioly Gassama, Seni Tamba. Review on Essential Oils and Their Corrosion-inhibiting Properties. American Journal of Applied Chemistry. Vol. 9, No. 3, 2021, pp. 65-73. doi: 10.11648/j.ajac.20210903.12

Received: May 20, 2021; Accepted: June 4, 2021; Published: June 21, 2021

\begin{abstract}
Natural and aromatic substances contained in plants which can be extracted by hydro-distillation or by cold extraction, more commonly known as essential oils are used today in several fields including cosmetic, perfumery, food processing, traditional medicine, agriculture etc. More recently, a strong use of these products extracted from plants as a corrosion inhibitor of metals and alloys in an acidic environment has been observed, given the number of works that have been published in recent decades. This review represents a general study on essential oils for a better understanding of these natural products, but also a non-exhaustive study of the published research works on the use of essential oils as a corrosion inhibitor of metals and alloys, in particular mild steels in acidic environments. Most of these studies have revealed great potentials of essential oils in inhibiting the corrosion of metals in aggressive environment, such as acidic environment. Thus, they have proposed alternatives to artificial metal corrosion inhibitor known to cause environmental pollution and public health issues. This review is a contribution to research efforts carried out by scientific community to find green corrosion inhibitors. It lays the basis for future research work aimed to investigate on the corrosion inhibition properties of essential oils extracted from Senegalese local plants.
\end{abstract}

Keywords: Essential Oil, Plant Extract, Corrosion Inhibitor, Metals, Steel, Acidic Environment

\section{Introduction}

An essential oil is the concentrated, hydrophobic liquid of a plant's volatile aromatic compounds. This liquid is mainly obtained by steam extraction, dry distillation or mechanical extraction [1].

Omnipresent in our daily life, the use of this fragrant liquid produced by plants dates back in several millennia, because the texts relating the use of essential oils are parchments dating of more than 1500 years BC. These parchments mention that the Egyptians used plant extracts in several areas of life, for example for the manufacture of perfumes, in the cosmetic field, a use as a remedy for certain diseases, but also use during religious ceremonies for the embalming of the deceased [2].

Today, the fields of use of essential oils have changed considerably as a result of more in-depth knowledge of these products. The perfumery and cosmetics industries are the main users of essential oils. Vegetal essential oil represents the basic ingredient for the production of perfume because of their pleasant smell, their high volatility and the fact that they do not leave a greasy trace. In traditional medicine, essential oils are highly coveted because of their antibacterial, antifungal and antiviral properties. In the food industry, there is also a strong presence of essential oils. But over the last few decades, a fairly new field of use has emerged: the use of these plant extracts as corrosion inhibitors of metals in an aggressive environment, which is a developing research focus based on the number of outgoing publications each year. Although several research works have already been developed to propose corrosion inhibitors, most of these inhibitors are synthetic compounds. Although these compounds exhibit good anti-corrosive activity, they are also toxic to humans and the environment [3]. Because of these concerns about these synthetic compounds, the researchers 
turned to more environmentally friendly solutions such as essential oils and, of course, other types of plant extracts. Since these products are considered to be green corrosion inhibitors because of the organic compounds they contain and their anti-corrosive properties, they are increasingly used to protect metals and alloys in a more or less acidic environment [4].

This work is oriented towards a general study of essential oils on the one hand and on the other hand to the various research works. The general study of essential oils is concerned with their characteristics, quality criteria and chemical compositions. This study also highlights production methods, and different methods for identifying the chemical compounds of essential oils. This second part focuses on the various research works carried out and published in the literature by researchers on the corrosion inhibiting properties of metals and alloys in an acid medium by essential oils.

\section{General Study of Essential Oils}

\subsection{Physicochemical Characteristics of Essential Oils}

Essential oils are considered to be very specific plant extracts, whose fields of application are very diverse, particularly in the medical, cosmetic and other fields [5]. These oils are liquid aromatic organic substances, highly concentrated in vegetal products that are found naturally in various parts of plants. They have the characteristics of being highly volatile compared to other known plant extracts, nonoily and susceptible to decomposition under relatively high temperature [6].

The numerous studies and research carried out by several authors on essential oils have made it possible to attribute to essential oils a certain number of properties. Essential oils are liquid at room temperature, volatile and steam-driven. The volatile character of these molecules gives the essential oil a very high fragrance. Although they are called oil, they do not contain any fat. The essential oils are $100 \%$ pure and natural. Essential oils have a density usually less than 1, therefore lighter than water. But for some essential oils, one may have a density greater than 1 . These dense oils than water are observed in oils with high phenols content and oils with high methyl salicylate content. In general most essential oils each have a characteristic smell that is quite pleasant. The miscibility of essential oils is total in alcohols and vegetal oils.

\subsection{Chemical Composition of Essential Oils}

From a chemical point of view, aromatic plants have a relatively complex composition. The organic compounds constituting these plants are represented by two distinct fractions due to their volatile or non-volatile character. A first so-called volatile fraction composed of secondary metabolites, called volatile organic compounds (VOCs), make up the essential oils. A second fraction contains nonvolatile organic compounds (NVOC). The VOC studies enabled the researchers to identify a complex mixture of these organic compounds. These organic substances may contain more than 300 different compounds. These volatile organic compounds belong to two large families.

The family of volatile terpenes whose precursor is mevalonic acid. Volatile terpenes are derived from isoprenic unit condensation [7]. In the class of terpenes, only monoterpenes $(\mathrm{C} 10)$ and sesquiterpenes $(\mathrm{C} 15)$ can be extracted by hydrodistillation. Diterpenes (C20) and triterpenes (C30) are not steam-driven [7]. The structure of terpenes' compounds is not identical for all. There are linear, monocyclic, bicyclic or tricyclic structures.

The second major family is the class of aromatic compounds derived from phenylpropane (C3-C6). These aromatic compounds are derived from the metabolism of shikimic acid, also called cinnamic acid. These compounds are much less common in essential oils compared to monoterpenes and sesquiterpenes. Among the most wellknown aromatic compounds of this class are vanilla, saffron, eugenol, anethol, estragole, etc.

Compounds from the degradation of non-volatile terpene during hydrodistillation can also be found in essential oils [8].

\subsection{Quality Criteria}

To ensure a good quality of an essential oil, it is necessary first of all to ensure the quality of the raw material implemented on the one hand and on the other hand the process of formulation of the finished product. Indeed, certain quality criteria must be met for both the raw material and the essential oil.

\subsubsection{Raw Material Quality Criteria}

Botanical species: For the plant used, a botanical certification written according to the international nomenclature under its Latin name specifying the genus, species and subspecies must be submitted [9]. This botanical certification is necessary because differences in chemical composition may occur depending on the botanical origin [10].

Geographical origin of the plant: Knowing the environment in which a plant grew, allows to characterize the extracted essential oil because a difference of chemical composition is observed according to the geographical origin and this is often due to the difference of geographical situation (altitude and latitude) or a difference in the nature of the soil [11].

Method of cultivation: This criterion defines whether the plant is cultivated or wild. It is often represented by a label if the plant comes from bio-agriculture [12]. This mode takes into consideration the growing, harvesting and storage conditions that have a direct impact both on the qualitative and quantitative aspect of the products that will be extracted from the plant.

Stage of Botanical Development: The biochemical composition of the essential oil generally depends on the stage of plant development, i.e., the time of collection of the plant before, during or after flowering [12]. 
Part of the distilled plant: It is possible to extract essential oil from all parts of the higher plants. Therefore, for the same plant, it is possible to produce essential oils with a different chemical composition and activity depending on the part of the distilled plant [13].

Chemotype of the plant: It allows to design distinct chemical entities within the same botanical species. The chemotype of an essential oil may affect its activity and/or toxicity. Therefore, it may be essential for some essential oils to specify the chemotype [14].

Plant identification: The identification of the raw material makes it possible to ensure a good traceability of the essential oil produced.

\subsubsection{Essential Oil Quality Criteria}

Technique for extracting essential oil: The technique used for extracting an essential oil largely determines its characteristics, in particular viscosity, colour, solubility, volatility but also future applications for this oil [15].

Physico-chemical characteristics of essential oils: These characteristics are criteria of qualities representative of essential oils. They are those that are generally common to all essential oils and which differentiate them from other oils commonly called fixed oils. Examples of these physicochemical characteristics include [15]:

1) The liquid state and volatility of essential oils at room temperature;

2) Lower density than water and relatively high refractive index;

3) A low solubility of essential oils in water, but nevertheless can be extracted by steam distillation;

4) Solubility in vegetable oils and organic solvents;

5) The carbon chains that make up essential oils contains over 5 to 22 carbon atoms.

\subsection{Distribution, Location and Function of the Essential Oil in the Plant}

Essential oils are present in all the vegetable species. They can be extracted from any part of a plant. So they have multiple origins. They are also subjected to diverse contacts with the external world. They are found in leaves (eucalyptus), fruits (pepper), seeds (nutmeg, coriander), wood (cedar, sandalwood), roots or rhizome (ginger), flowering tops (lavender, mint, etc.) [16].

Research that has already been carried out on plants and essential oils has shown that these are developed within the cytoplasm of certain cells and they separate from it by syneresis which is a process of separation of a liquid from its gel. This separation is done in the form of small droplets that confluent in more or less extended range and are then stored in specialized cellular structures such as glandular trichomes, isolated secreting cells (lauraceae, magnoliaceae), secretory vesicles and secretory pathways [17].

Specialists working in the plant field believe that the production of essential oil by the plant is not only intended for human use. They are primarily considered sources of chemical signals that allow the plant to control or regulate its environment. According to the studies carried out by these specialists, the actions that can be linked to the production of essential oil by a plant are:

1) The attraction of pollinating insects;

2) The repulsion of predators and protection of the plant against certain diseases due to their antifungal, antiviral, antibacterial or insect repellent properties;

3) Inhibition of seed germination and in some cases, a means of communication between plants (emission of chemical signals);

4) Use as an energy reserve by the plant under adverse climatic conditions [18].

\subsection{Method of Extraction of Essential Oils}

The extraction of essential oils is done with yields that are generally very low (of the order of 1 to $3 \%$ ), which makes them rare and precious products. The extraction techniques for essential oils must therefore take account of these characteristics and certain parameters such as volatility, solubility, size and shape of the constituent molecules, but they must also be able to provide satisfactory quantitative performance [19].

Extraction techniques for essential oils are presented according to the principles on which they are based. These extraction techniques can then be classified into two categories. The first category of techniques is based on steam distillation. The second category is cold extraction techniques.

\subsubsection{Hydrodistillation Technique}

This is the oldest and most widely used technique for the extraction of essential oils. To date, this technique is known in three different forms: hydro-distillation, steam extraction and hydro-diffusion [20].

Hydro-distillation: The principle of this technique consists in immersing the vegetable raw material in a flask during an extraction in the laboratory or in an industrial still filled with water placed on a source of heat. It is heating that will allow the release of the aromatic molecules contained in the raw material by the bursting of plant cells and the aromatic molecules form with water vapor, an azeotropic mixture. The vapors are condensed in a refrigerant, and the essential oils separated from the water by density difference [21]. It should be noted that the yield and composition of the extracts is highly dependent on the duration of hydro-distillation. For raw materials where essential oils or essences are difficult to extract, high-pressure hydro-distillation is generally used [22].

Steam extraction: As with hydro-distillation, this technique is considered one of the official methods of extraction of essential oils. But unlike hydro-distillation, water and plant material are not in direct contact. The raw material placed on a grid is crossed by water vapor supplied by a boiler. The steam from the boiling water carries the vapor of the essential oils to a condenser; both are cooled and return to the liquid state, they will spontaneously form a distinct phase after condensation, allowing them to be separated by decantation or with a separatory funnel [23]. The absence of direct 
contact between water and plant material, and then between water and aromatic molecules prevents certain phenomena like hydrolysis or degradation of the organic compounds that can affect the quality of the product [23].

Hydro-diffusion: It represents a variant of volatile compound extraction technique. This relatively recent and particular technique involves the osmotic action of water vapor. It consists in passing, from the top to the bottom and at reduced pressure, the water vapor through the vegetable matter. It has the advantage of saving time and energy. This technique also has a permanent recycling system for distillation water [24].

This list of extraction techniques based on the principle of water distillation is not exhaustive, because in the literature there are new emerging techniques based on classical distillation techniques. However, these techniques usually require very specific devices and more specific working conditions. These special conditions make it possible either to increase the efficiency of the products, or to improve their quality, or to save time and energy.

\subsubsection{Cold Extraction Techniques for Essential Oils}

This is a fairly simple technique to implement but also quite limited compared to the techniques of water vapor distillation. It is reserved for the extraction of the compounds contained in the pericarps of the skippers or of the citrus fruits which have a great importance for perfumes and cosmetics industries. But these compounds are very fragile because of their terpene composition. The extraction process is based on the rupture of the walls of the oil-bearing vesicles contained in the peel of the fruit. The released essential oil is collected by a stream of water which will carry all the compounds usually obtained with the steam distillation techniques. That's why specialists called this product essential oil [25].

\subsection{Method for Identifying Chemical Compounds Constituting Essential Oils}

The valorization of an essential oil is generally preceded by a qualitative characterization step. The quality of an essential oil is closely linked to its chemical composition. It is therefore necessary to know the chemical composition of an essential oil after its extraction.

Analysis of essential oils is based on separation and identification of constituents by chromatographic and/or spectroscopic techniques. Gas chromatography (GC) or coupled with other spectral (mass spectrometry) (GC/MS) techniques are most commonly used for essential oil routine analyses.

Gas chromatography (GC): It is defined as a method of analysis by separation that applies to gaseous compounds or that may be vaporized by heating without decomposition. It is a widely used separation technique due to its sensitivity and individualization of volatile compounds of highly complex mixtures as in the case of essential oils. Gas chromatography combined with a flame ionization detector allows in addition to identification, a quantitative analysis of the constituents of the mixture on the basis of the area of each chromatographic peak against the total signal area, and a qualitative analysis on the basis of retention times. As far as identification is concerned, it is carried out by comparing their polar (Ir p) and apolar ( Ir a) retention indices calculated from the retention times of a range of alkane standards or, more rarely, linear methyl esters, at constant temperature or in temperature programming (Ir retention index) with that of reference products contained in commercial libraries or described in laboratory-level literature [26].

Coupling gas chromatography to mass spectrometry (GC/MS): This is the most widely used technique in the field of essential oils characterization. Its principle is based on the possibility, after the separation of the compounds carried out by the GC, to perform directly by means of mass spectrometer (MS) an ionization of each of isolated molecule. It therefore makes it possible to obtain structural information relating to each compound and consequently its identification by comparing its mass spectrum with those of reference products contained in spectra libraries [27].

Other coupling techniques: In the literature, there are more and more new coupling techniques in recent decades. Indeed, many difficulties are encountered when analyzing complex mixtures in the different fields.

The combination of known techniques and methods has recently led to the development of the coupling of GC with a Fourier transform infrared FT-IR spectrometer (GC/FT-IR) which is a fairly complementary technique of GC/MS. Infrared spectroscopy provides information on the chemical functions present in molecules and also makes it possible to differentiate isomers. Efficacy has been demonstrated for the study of molecules with overlapping mass spectra such as farnesyl and menthol stereoisomers [28].

Multidimensional double analyzer (MS/MS) or tandem mass spectrometry is also one of the implemented coupling techniques found in the literature. This technique can be used for essential oils and consists of selecting the ions corresponding to a chosen $\mathrm{m} / \mathrm{z}$ ratio by means of a first analyzer which thus plays the role of a filter and sending them on a second analyzer. Fragments of the secondary ion constitute a second mass spectrum which differs according to the origin of the primary ion [29].

Other coupling techniques include that coupling GC to with mass spectrometer and an infrared detector (GC/IRFT/MS) [30, 31].

\subsection{Essential Oils Corrosion Inhibition Mechanism}

The corrosion inhibition mechanism of essential oils and other plant extracts is related to a number of basic considerations valid for all corrosion inhibitors:

1) Since corrosion is an essentially electrochemical process, the action of the inhibitor can only be carried out at one of the elementary reaction stages (transport of species in solution, transfer of electronic charges, adsorption of species to the surface of solid phases, formation of superficial intermediaries),

2) Since the intervention of the inhibitor in the process of 
transport of the electro-active species (oxygen, protons, reaction products) within the solution is unlikely, the action of an inhibitor is most often to be sought in the immediate vicinity of the surface.

As a result, the mechanism of action and inhibitory efficacy of essential oils is often linked to the presence of active constituents causing either a formation of a passivating layer on the surface of the metal or an improvement of an existing passivating, thus allowing the corrosion reduction [32], and this by adsorption mechanism. The adsorption of essential oils molecules at the metal/solution interface can be done either by chemisorption mechanism, i.e., by a chemical interaction mechanism (electron exchange and chemical bond formation) between metal surface atoms and inhibitor atoms, or by physisorption mechanism, i.e., by physical interaction mechanism (van der Waals forces) between ions contained in the solution and the surface of metal or as a combination of both mechanisms. The adsorption process is affected by the chemical structures of the essential oils' molecules, the nature of the metal and the distribution of the charges on all inhibiting molecules [33].

The action of the inhibitor can thus be: [34]

1) the interposition of a barrier between the metal and the corrosive medium, in this case, which is essentially that of the acidic media, the role of surface adsorption will be paramount;

2) the formation of a barrier by interaction between the inhibitor and one or more species of the corrosive medium, this type of mechanism is specific to neutral media;

3) Formation of a continuous layer on the metal surface by chemical bonding from molecules with long carbon chains carrying polar groups at both ends;

4) addition of buffers, which increase the $\mathrm{pH}$ near the metal surface and promote passivation in some cases: some oxidizing inhibitors cause a spontaneous passivation of the metal thus decreasing the rate of corrosion;

5) The formation of surface films by precipitation of mineral salts or poorly soluble organic complexes.

\section{Corrosion Inhibition by Essential Oils}

Most of the corrosion inhibitors used to date in the industrial field are synthesized from raw materials from organic compounds with heteroatoms such as nitrogen, sulphur, phosphorus or oxygen in their aromatic system or carbon chain. These anti-corrosive substances are generally toxic to humans and the environment [35]. The toxicity of these compounds occurs during synthesis or during their applications. In addition, since these substances are not biodegradable, a pollution problem arises.

Strict environmental laws and environmental awareness in the scientific world have directed researchers to develop other forms of so-called "green" inhibitors. Recently, various parts of plants, leaves, fruits, seeds and flowers were extracted and used as corrosion inhibitors [36-46]. Therefore, in recent years there has been a particular interest in the activity of essential oils as a corrosion inhibitor of steel in hydrochloric acid [47-52]. They have the advantage of being biodegradable, non-toxic and environmentally friendly. A lot of work has been published recently in this area.

A review of the literature shows that studies in this area are quite promising with fairly high inhibitory efficacy rates for essential oils. Studies on tea-tree essential oil have shown that the inhibitory efficiency on steel in hydrochloric acid (1 M) media increases with the increase in concentration to a maximum value of $96 \%$ at $2 \mathrm{~g} / \mathrm{L}$ of essential oil at a temperature of $298 \mathrm{~K}$ [53].

Ben Hmamou et al [54], obtained an efficiency on C38 steel in acid medium (HCL) $1 \mathrm{M}$ up to $90 \%$ with $2 \mathrm{~g} / \mathrm{L}$ of chamomile (Chamomillarecutita) essential oil. Their study showed that temperature has no influence on the efficiency rate.

The use of the essential oil of Mentha spicataL by Znini et al [55], revealed an inhibitory effectiveness of steel corrosion in $\mathrm{HCl}$ medium (1 M) up to $97 \%$ for $2 \mathrm{~g} / \mathrm{L}$ of inhibitor at 298 $\mathrm{K}$. However, a decrease in this efficiency was observed at relatively high temperatures (from 303 to $333 \mathrm{~K}$ ). The assessment of the anti-corrosion activity of white sagebrush (Artemisia Herba Alba) essential oil, on the corrosion of steel in three different acids, has also been carried out by several authors using gravimetric measurements and the combination of polarization and electrochemical impedance methods. indeed, Ouachikh et al [56], studied this essential oil in 0,5 M $\mathrm{H}_{2} \mathrm{SO}_{4}$. The results revealed that this oil reduces the corrosion rate by cathodic action. Inhibition efficiency increases with temperature and oil concentration to reach $74 \%$ at $1 \mathrm{~g} / \mathrm{L}$. Boudiala et al [57], worked on the essential oil they extracted from the aerial parts of Artemisia herba-alba from Morocco. This essential oil was tested as a corrosion inhibitor of stainless steel (SS) in HCL acid (1 M) using potentiodynamic polarization (PDP) measurements, electrochemical impedance spectroscopy (EIS) and scanning electron microscopy studies (SEM). The results showed that Artemisia's essential oil reduces the corrosion rate. Inhibition efficiency increased with inhibitor concentration and achieved $88 \%$ with $1 \mathrm{~g} / \mathrm{L}$ of substance.

The corrosion behaviour of steel in $\mathrm{HCl}(1 \mathrm{M})$ in the presence of mint fowl (Menthapulégium) essential oil was evaluated by Bouyanzer et al [58], using gravimetric measurements, polarization curves and electrochemical impedance. Indeed, the inhibition efficiency increases with the oil content, and reach $80 \%$ at $2.76 \mathrm{~g} / \mathrm{L}$, indicating that this essential oil is a good inhibitor.

The inhibition of corrosion of $\mathrm{C} 38$ steel in $\mathrm{H}_{2} \mathrm{SO}_{4}$ (sulphuric acid) solution by the essential oil of Eucalyptus globulus (Myrtaceae) was investigated by Rekkab et al [59], using weight loss techniques, electrochemical impedance spectroscopy and potentiodynamic polarization. The inhibition efficiency increases with the increase in the concentration of essential oil to reach $75.8 \%$ to $6 \mathrm{~g} / \mathrm{L}$. The effect of temperature on the corrosion behaviour of $\mathrm{C} 38$ steel in $0.5 \mathrm{M} \mathrm{H}_{2} \mathrm{SO}_{4}$ with addition of essential oil was also 
studied over the temperature interval (298-328 K). They found a decrease in the inhibitory effectiveness of essential oil with the increase in temperature.

The inhibition behaviour of lead corrosion in $0.1 \mathrm{M}$ $\mathrm{Na}_{2} \mathrm{CO}_{3}$ solution by Atlas cedar (Cedrus atlantica) essential oil was studied by I. El-miziani et al [60] using the polarization curve technique and impedance technique. The corrosion rate decreases and the inhibition efficiency increases with oil concentration, and an inhibition efficiency of $70 \%$ was reached at a concentration of $2000 \mathrm{ppm}$.

The inhibitory action of the essential oil of Salvia aucheri mesatlantica on the corrosion of the steel in $0.5 \mathrm{M} \mathrm{H}_{2} \mathrm{SO}_{4}$ solution was studied by Znini et al [61], using weight loss measurements and electrochemical techniques. The results obtained indicated that the inhibitory efficiency increases with the concentration of essential oil to reach $86.12 \%$ at $2 \mathrm{~g} / \mathrm{L}$.

The inhibitory capacity of fennel essential oil (foeniculum vulgaris) on corrosion of steel in $\mathrm{HCl}(1 \mathrm{M})$ was studied by Lahhit et al [62], using gravimetric method and coupling of stationary and transient electrochemical techniques. The results obtained indicated that the corrosion rate decreases and the inhibitory efficiency increases with the increase in essential oil concentration to $76 \%$ at $3 \mathrm{ml} / \mathrm{L}$.

The inhibitory action of vervain essential oil on the corrosion of $\mathrm{C} 38$ steel in HCL $1 \mathrm{M}$ solution in the temperature range 298-328 k was measured by Ben Hmamou et al [63]. This work used methods of weight loss, potentiodynamic polarization and electrochemical impedance spectroscopy. The results showed that the inhibitory efficiency increases with the increase in the inhibitor concentration, but decreases with temperature.

El Ouariachi et al [64], evaluated the inhibitory power of Rosmarinus officinalis essential oil on the corrosion of steel in $0.5 \mathrm{M} \mathrm{H}_{2} \mathrm{SO}_{4}$ using weight loss measurements, and electrochemical polarization methods. The results obtained indicate that the effectiveness of inhibition increases with the increase in oil concentration, and reach $61 \%$ at $1 \mathrm{~g} / \mathrm{L}$. The effectiveness of oil inhibition remains slightly constant with the increase in temperature.

The work of L. Majidi et al [65], focused on the essential oil of aerial parts of Helichrysum italicum subsp. italicum (HI) obtained by hydrodistillation and analyzed by GC and GC/MS. An inhibitory effect was found, and its efficiency increased with concentration of the essential oil to reach $82.33 \%$ at $2 \mathrm{~g} / \mathrm{L}$. The effect of temperature on the corrosion behaviour of mild steel in $\mathrm{HCl}(1 \mathrm{M})$ without and with essential oil at $2 \mathrm{~g} / \mathrm{L}$ was also studied.

Studies conducted by Loto et al [66] have shown a synergistic effect of essential oils extracted from clove, basil and atlas cedar. The corrosion inhibition properties of this mixed essential oils was studied on steel with low grade carbon in $0,5 \mathrm{M} \mathrm{H}_{2} \mathrm{SO}_{4}$ et $\mathrm{HCl}$ solutions. The results showed that the two mixed inhibitor compounds functioned effectively at various concentrations with optimal inhibition efficiencies of $95.48 \%$ and $95.32 \%$ in $\mathrm{H}_{2} \mathrm{SO}_{4}$ solution, while in $\mathrm{HCl}$ the corresponding values are $92,7 \%$ and $97.98 \%$. R-T Loto et al [67], also conducted studies on combined effect of essential oils derived from salvia officinalis and simmondsia chinensis. They assessed their corrosion inhibition performance at low concentration on mild steel in $1 \mathrm{M}$ of $\mathrm{H}_{2} \mathrm{SO}_{4}$.

The results obtained from the electrochemical test showed an optimal inhibition efficiency of this mixture of $86.58 \%$ and $83.29 \%$ to $6 \%$ and $5 \%$ volumetric concentration, respectively. The inhibition performance of Citrus sinensis (CS) essential oil on ordinary carbon steel (PCS) corrosion in $0.5 \mathrm{M} \mathrm{H}_{2} \mathrm{SO}_{4}$ and $0.5 \mathrm{M} \mathrm{HCl}$ solution was evaluated by R-T Loto et al [68]. Several assessment techniques have been used, and weight loss measures revealed an optimal inhibition result of $81.61 \%$ in $\mathrm{HCl}$ and $76.95 \%$ in $\mathrm{H}_{2} \mathrm{SO}_{4}$. Inhibition efficiency generally decreases with respect to exposure time, but increases with increased inhibitor concentration in both acids.

Ptychotis verticillata essential oil was tested as a mild steel corrosion inhibitor in $\mathrm{HCl}$ (1 M) by E. El Ouariachi et al [69]. Weight loss measurement, electrochemical impedance spectroscopy, and potentiodynamic bias curves were used to evaluate corrosion inhibition. They found that the effectiveness of the inhibition increases with the increase in inhibitor concentration, due to the adsorption of inhibitory molecules on the metallic surface. In $1 \mathrm{M} \mathrm{HCl}$ the inhibition efficiency was $74.6 \%$ at $1.08 \mathrm{~g} / \mathrm{L}$ of essential oil. The major compounds of this essential phenolic molecules (48\%).

\section{Conclusion}

This work represents a scientific literature review to allow a better understanding of essential oils: chemical composition, extraction techniques, characterization methods and uses in different domains. About the later, number of studies have been conducted over the past two decades on the use of essential oils as green corrosion inhibitors in acidic environments for different types of steels and alloys. It has been found that these natural corrosion inhibitors showed almost the same efficacity as synthetic inhibitors, for instance most essential oils gave a corrosion inhibition rate higher than $90 \%$ in acid medium. Moreover, these natural inhibitors that are plant extracts, especially essential oils are environmentally friendly, which would allow their uses to resolve the toxicity and environmental impacts of synthetic inhibitors.

\section{References}

[1] AFNOR, 2000- huile essentielle. Association française de normalisation. Paris. Pp 559-563.

[2] Heath, H. B., 1981. Source Book of Flavours. Westport: Avi, Pp 890.

[3] Ostovari, A., Hoseinieh, S. M., Peikari, M., Shadizadeh, S. R., Hashemi, S. J., Corrosion Science, 51 (2009) 1935-1949.

[4] Abiola, O. K., Tobun, Y., Chinese Chemical Letters, 21 (2010) 1449-1452.

[5] Aurore, S. T., Emission «ASTUCES SANTE» - www.rcf.fr. 
[6] Turgeon, M., «Profil des produits forestiers première transformation des huiles essentielles» 2001-3086 (Déc 2001) p. 1.

[7] Françoise, C. M., Annelise, L., «Composition chimique des huiles essentielles», Elsevier Masson SAS (2013).

[8] Bruneton, J., 1993. Pharmacognosie: Phytochimie, Plantes médicinales. 2eme édition. Technique et Documentation Lavoisier, Paris: 387-404.

[9] TEUSCHER E., ANTON R., LOBSTEIN A. Plantes aromatiques: épices, aromates, condiments et huiles essentielles. Lavoisier Tec et Doc, Paris, 2005.

[10] F, MAYER: Utilisations thérapeutiques des huiles essentielles: ETUDE DE CAS EN MAISON DE RETRAITE (2012).

[11] FRANCHOMME, P., JOLLOIS, R., PENOEL, D., «L'aromathérapie exactement: Encyclopédie de l'utilisation thérapeutique des huiles essentielles.» Editions Jollois, 2001.

[12] A. F. S. S. A. P. S. afssaps.santé.fr: Recommandations huiles essentielles.

[13] BRUNETON, J., «Pharmacognosie, phytochimie, plantes médicinales, 3ème édition», Lavoisier Tec et Doc, Paris, 1999.

[14] WICHTL, M. et ANTON, R., «Plantes thérapeutiques 2ème Edition», Lavoisier Tec et Doc, Paris, 2003.

[15] A. F. S. S. A. P. S. afssaps.santé.fr: Recommandations relatives aux critères de qualité des huiles essentielles, Mai 2008.

[16] BELAKHDAR, J., «La pharmacopée marocaine traditionnelle». Idis PRESS (Ed). Paris, p. 764, 1997.

[17] Degryse A. C., Delpla I. \& Voinier M. A., «Risques et bénéfices possibles des huiles essentielles.» Atelier santé environnement -IGS- EHESP, 2008.

[18] C Desfemmes. gerbeaud.com: «Pourquoi certaines plantes sont-elles aromatiques ?», Juillet 2014.

[19] A. EL HAIB: UNIV. DE TOULOUSE: VALORISATION DE TERPENES NATURELS ISSUS DE PLANTES MAROCAINES PAR TRANSFORMATIONS CATALYTIQUES (2011).

[20] Silou, T., Malanda, M., Loubaki, L., «Optimisation de l'extraction d'huile essentielle de cymbopogon citratus grace à un plan factoriel complet 23». Journal of food engineering, 2004.

[21] Pavida, D. L., Lampman, G. M., Kriz, G. S., «Introduction to organic laboratory techniques», $W . \quad B$. Sauders Co. Philadelphia, USA. 1976, 567.

[22] Lucchesi, M E., «Extraction Sans Solvant Assistée par microondes conception et application à l'extraction des huiles essentielles», thèse doctorat: Université de la Réunion, France, 2005.

[23] Roldan-Gutiérres, J. M., Ruiz-Jiménez, J., Luque de Castro, M D., 2008 «Ultrasoundassisted dynamic extraction of valuable compouds from aromatic plants and flowrs as compared with steam distillation and superheated liquid extraction», Talanta, 2008 .

[24] Nabil Bousbia. «Extraction des huiles essentielles riches en anti-oxydants à partir de produits naturels et de co-produits agro-alimentaires», Université d'Avignon, 2011. Français.
ffNNT: 2011AVIG0243ff. fftel-00915117f.

[25] Wang, Z., Ding, L. Li. T., Zhou, L X., Zhang, W. H., Liu, L., Li, Y., Liu, Z., Wang, H., Zeng, H,. He, H., Chrom, J. A., 2006, 1102.

[26] Joulain, D., König, W. A., 1998. «The atlas of spectral data of sesquiterpene hydrocarbons». EbVerlag Hamburg.

[27] Adams, R. P., «Identification of essential oil components by gaz chromatography / quadrupole mass spectroscopy.» Allured Publ. Crop., Carol Stream, IL, USA, 2004.

[28] Coleman, W. M., Gordon, B. M., Lawrence B. M., «Examinations of the matrix isolation fourier transform infrared spectra of organic compounds: part XII» Appl. Spectrosc. 43: 298-304, 1989.

[29] Sylvain Sutour. «Etude de la composition chimique d'huiles essentielles et d'extraits de menthe de Corse et de Kumquats. Chimie» Université de Corse, 2010. Français. fftel00603340 .

[30] Dugo, G., Tranchida, P., Cotroneo, A., Dugo, P., Bonaccorsi, I., Marriott, P., Shellie, R. et Mondello, L. (2005) "Advanced and innovative chromatographic techniques for the study of citrus essential oils." Flavour and Fragrance Journal, 20: 249-264.

[31] M. ZNINI: Thèse Doctorat, Université Moulay Ismaïl, Faculté des sciences et technique (2011).

[32] O. L. Riggs. Jr., Corrosion Inhibitors, 2nd Editio, C. C. Nathan, Houston, 1973.

[33] M. Znini., «Application of EOs as green corrosion inhibitors for metals» Arabian Journal of Medicinal \& Aromatic Plants V5N3, 2019.

[34] F. Christian., «Inhibiteurs de corrosion», Techniques de l'Ingénieur, Méthodes de prévention et lutte contre la corrosion, Article / Réf: COR1005 v1.

[35] D. Landolt, Corrosion et Chimie de Surface des Métaux, 1st Edition, Alden Press, Oxford, (1993) 499.

[36] A. El-Etre. (2007). Inhibition of acid corrosion of carbon steel using aqueous extract of olive leaves. Journal of Colloid and Interface Science, 314 (2), 578-583.

[37] J. C. Da Rocha, J. A. d. C. P. Gomes, and E. D'Elia. (2010). Corrosion inhibition of carbon steel in hydrochloric acid solution by fruit peel aqueous extracts. Corrosion Science, 52 (7), 2341-2348.

[38] A. Zaabar, R. Aitout, L. Makhloufi et al. (2014). Inhibition of acid corrosion of mild steel by aqueous nettle extracts. Pigment \& resin technology, 43 (3), 127-138.

[39] A. A. Koffi, S. Muralidharan, and A. Trokourey. (2015). Corrosion inhibition of carbon steel using extract of Mussaenda erythrophylla leaves: interfacial action mode in sulfuric acid medium/Inhibition de la corrosion de l'acier à l'aide d'extrait de feuilles de Mussaenda erythrophylla: mode d'action interfaciale en milieu acide sulfurique, Journal de la Société Ouest-Africaine de Chimie, 40, 31.

[40] K. Shalabi, and A. A. Nazeer. (2015). Adsorption and inhibitive effect of Schinus terebinthifolius extract as a green corrosion inhibitor for carbon steel in acidic solution. Protection of Metals and Physical Chemistry of Surfaces, 51 (5), 908-917. 
[41] M. Prabakaran, S.-H. Kim, K. Kalaiselvi et al. (2016). Highly efficient Ligularia fischeri green extract for the protection against corrosion of mild steel in acidic medium: Electrochemical and spectroscopic investigations. Journal of the Taiwan Institute of Chemical Engineers, 59, 553-562.

[42] A. Fouda, A. Abousalem, and G. El-ewady. (2017). Mitigation of corrosion of carbon steel in acidic solutions using an aqueous extract of Tilia cordata as green corrosion inhibitor. International Journal of Industrial Chemistry, 8 (1), 61-73.

[43] P. Muthukrishnan, B. Jeyaprabha, and P. Prakash. (2017). Adsorption and corrosion inhibiting behavior of Lannea coromandelica leaf extract on mild steel corrosion. Arabian Journal of Chemistry, 10 S2343-S2354.

[44] T. Bhuvaneswari, V. Vasantha, and C. Jeyaprabha. (2018). Pongamia Pinnata as a green corrosion inhibitor for mild steel in 1N sulfuric acid medium. Silicon, 10 (5), 1793-1807.

[45] M. Prabakaran, S.-H. Kim, A. Sasireka et al. (2018). Polygonatum odaratum extract as an eco-friendly inhibitor for aluminum corrosion in acidic medium. Journal of adhesion science and Technology, 32 (18), 2054-2069.

[46] Y. Qiang, S. Zhang, B. Tan et al. (2018). Evaluation of Ginkgo leaf extract as an eco-friendly corrosion inhibitor of X70 steel in $\mathrm{HCl}$ solution. Corrosion Science, 133, 6-16.

[47] Bammou, L., Chebli, B., Salghi, R., Bazzi, L., Hammouti, B., Mihit, M., Idrissi, H. (2010). Thermodynamic properties of Thymus satureioides essential oils as corrosion inhibitor of tinplate in $0.5 \mathrm{M} \mathrm{HCl}$ : chemical characterization and electrochemical study. Green Chemistry Letters and Reviews, 3 (3), 173-178.

[48] Bammou, L., Mihit, M., Salghi, R., Bouyanzer, A., Al-Deyab, S. S., Bazzi, L., Hammouti, B. (2011). Inhibition effect of natural Artemisia oils towards tinplate corrosion in HCL solution: chemical characterization and electrochemical study. International Journal of Electrochemical Science, 6, 1454-1467.

[49] Gualdrón, A. F., Becerra, E. N., Peña, D. Y., Gutiérrez, J. C., Becerra, H. Q. (2013). Inhibitory effect of Eucalyptus and Lippia alba essential oils on the corrosion of mild steel in hydrochloric acid. Journal of Materials and Environmental Science, 4 (1), 143-158.

[50] Lahhit, N., Bouyanzer, A., Desjobert, J. M., Hammouti, B., Salghi, R., Costa, J., Jama, C., Bentiss, F., Majidi, L. (2011). Fennel (Foeniculum vulgare) essential oil as green corrosion inhibitor of carbon steel in hydrochloric acid solution. Portugaliae Electrochimica Acta. 29 (2), 127-138.

[51] Potgieter, J. H., Olubambi, P. A., Thanjekwayo, N. P. (2012). Investigation of the potential of some plant extracts to inhibit the corrosion of duplex stainless steels in acidic media. Journal of Metallurgical Engineering, 1 (2), 41-47.

[52] Znini, M., Bouklah, M., Majidi, L., Kharchouf, S., Aouniti, A., Bouyanzer, A., Al-Deyab, S. S. (2011). Chemical composition and inhibitory effect of Mentha spicata essential oil on the corrosion of steel in molar hydrochloric acid. International Journal of Electrochemical Science, 6 (3): 691-704.

[53] Nasser Otaifah, Yaaqob. (2016). Etude de l'inhibition de l'acier C38 par de l'huile essentielle en milieu acide $(\mathrm{HCl}) 1 \mathrm{M}$.

[54] Ben Hmamou, D., Salghi, R., Zarrouk, A., Hammouti, B., AlDeyab, S. S., Bazzi, Lh., Zarrok, H., Chakir, A., Bammou, L., Int. J. Electrochem. Sci., 7 (2012) $2361-2373$.
[55] Znini, M. \& Bouklah, M. \& Majidi, Lhou \& Kharchouf, S \& Aouniti, A \& Bouyanzer, A. \& Hammouti, B. \& Costa, Jean \& Al-Salem, Sultan. (2011). Chemical Composition and Inhibitory Effect of Mentha Spicata Essential Oil on the Corrosion of Steel in Molar Hydrochloric Acid. Int. J. Electrochem. Sci. International Journal. 6. 691-704.

[56] O. Ouachikh, A. Bouyanzer, M. Bouklah, J. M. Dexjobert, J. Costa, B. Hammouti, L. Majidi. Surf. Rev. Lett. 16 (01), 2009: 49-54.

[57] M. Boudalia, R-M. Fernández-Domene, M. Tabyaoui, A. Bellaouchou, A. Guenbour, J. García-Antón «Green approach to corrosion inhibition of stainless steel in phosphoric acid of Artemesia herba albamedium using plant extract» Journal of Materials Research and Technology Volume 8, Issue 6, November-December 2019, Pages 5763-5773.

[58] Bouyanzer, A., Hammouti, B., Majidi, L., Materials Letters, 60 (2006) 2840-2843.

[59] S. Rekkab, H. Zarrok, R. Salghi, A. Zarrouk, Lh. Bazzi, B. Hammouti, Z. Kabouche, R. Touzani, M. Zougagh (2012) Green Corrosion Inhibitor from Essential Oil of Eucalyptus globulus (Myrtaceae) for C38 Steel in Sulfuric Acid Solution. J. Mater. Environ. Sci. 3 (4) (2012) 613-627.

[60] I. Elmiziani, S. Houbairi, M. Essahli, A. Lamiri, S. Lhaloui, A. Lamiri, «Lead corrosion inhibition by cedrus atlantica as a green inhibitor in $0.1 \mathrm{M} \mathrm{Na} \mathrm{Na}_{2} \mathrm{CO}_{3}$ solution» International Journal of Advanced Chemistry. 5 (2017) 1-7.

[61] M. Znini, L. Majidi, A. Bouyanzer, J. Paolini, J-M. Desjobert, J. Costa, B. Hammouti: Essential oil of Salvia aucheri mesatlantica as a green inhibitor for the corrosion of steel in $0.5 \mathrm{M} \mathrm{H}_{2} \mathrm{SO}_{4}$ 10.1016/j.arabjc.2010.09.017.

[62] Lahhit, N. and al. Fennel (Foeniculum Vulgare) Essential Oil as Green Corrosion Inhibitor of Carbon Steel in Hydrochloric Acid Solution. Port. Electrochim. Acta [online]. 2011, vol. 29, n. 2, pp. 127-138. ISSN 0872-1904.

[63] Dris Ben Hmamou, Rachid Salghi, Abdelkader Zarrouk, Hassan Zarrouk, Mohamed Errami, Belkheir Hammouti, Laila Afia, Lhoucine Bazzi, Lahcen Bazzi. Acta Metall. Sin.(Engl. Lett.) Vol. 23 No 1 pp 13-20 February 2010.

[64] E. El Ouariachi, J. Paolini, M. Bouklah, A. Elidrissi, A. Bouyanzer 1), B. Hammouti, J-M. Desjobert and J. Costa Adsorption properties of Rosmarinus officinalis oil as green corrosion inhibitors on $\mathrm{C} 38$ steel in $0.5 \mathrm{M} \mathrm{H}_{2} \mathrm{SO}_{4}$ Acta Metall. Sin. (Engl. Lett.) Vol. 23 No. 1 pp 13-20 February 2010 .

[65] Cristofari, G \& Znini, M. \& Majidi, Lhou \& Costa, Jean \& Hammouti, B. \& Paolini, Julien. (2012). Helichrysum italicum subsp. italicum Essential Oil as Environmentally Friendly Inhibitor on the Corrosion of Mil Steel in Hydrochloric Acid. International Journal of Electrochemical Science. 7.

[66] R-T. Loto, T. Olukeye, E. Okorie «Synergistic combination effect of clove essential oil extract with basil and atlas cedar oil on the corrosion inhibition of low carbon steel» South African Journal of Chemical Engineering Volume 30, October 2019, Pages 28-41.

[67] R-T. Loto, O. Olowoyo «Corrosion inhibition properties of the combined admixture of essential oil extracts on mild steel in the presence of $\mathrm{SO}_{4}{ }^{2-}$ anions» Volume 26, December 2018, Pages 35-41. 
[68] R-T. Loto, E-H. Mbah, J-I. Ugada «Corrosion inhibition effect of citrus sinensis essential oil extract on plain carbon steel in dilute acid media» Available online 30 August 2020.

[69] Ouariachi, El \& Bouyanzer, A. \& Salghi, Rachid \& Hammouti,
B. \& Desjobert, J.-M \& Costa, Jean \& Paolini, Julien \& Majidi, Lhou. (2015). Inhibition of corrosion of mild steel in $1 \mathrm{M} \mathrm{HCl}$ by essential oils or solvent extracts of Ptychotis Verticillata. Research on Chemical Intermediates. 41. 10.1007/s11164-013-1246-5. 